Revista de Investigación Científica

Universidad Nacional de Tumbes

\title{
EDITORIAL
}

\section{Manglar - Reto con la Ley Universitaria 30220}

La investigación científica es una tarea obligatoria que siempre han tenido todas las universidades como centros de formación superior, y es una función de sus docentes y estudiantes el desarrollar proyectos de investigación básica o aplicada, y ya sea descriptiva o experimental; que conlleven a dar solución de los diversos problemas que aquejan a la sociedad. Si tenemos en cuenta que, actualmente en nuestro país se está aplicando la nueva ley universitaria: Ley № 30220, norma que pone como pilar obligatorio para el licenciamiento de las universidades, la investigación científica se tendrá que realizar en todos sus niveles (para que la institución obtenga el permiso de funcionamiento; caso contrario será cerrada); en este argumento es preciso, que en la Universidad Nacional de Tumbes los estamentos nos pongamos a trabajar en este aspecto, a fin de formar profesionales competentes, buscando dar solución con prioridad a los problemas del Departamento de Tumbes y del país.

La Ley № 30220, exige a los estudiantes dos trabajos de investigación, uno para obtener el grado de bachiller y el otro para el título profesional, razón suficiente para que los docentes de esta casa superior de estudios hagamos investigación científica que los motive, para que analicen los problemas más apremiantes a fin de darles solución. Con una buena base de formación profesional en la especialidad, motivación y perseverancia, así como con el apoyo del profesor asesor se logrará perfeccionar las competencias investigativas; para que contribuyan al desarrollo del país.

Estoy seguro que con esta exigencia de la nueva ley universitaria, en un plazo muy corto la Revista Científica MANGLAR, tendrá suficientes artículos, provenientes de los trabajos realizados por los docentes y los estudiantes, para publicar con mayor frecuencia; y se espera que luego cada Facultad edite su propia revista científica.

En el corto tiempo que he pasado por la Oficina General de Investigación, ahora (con el nuevo Estatuto de la Universidad) dentro del Instituto de Investigación y Desarrollo Tecnológico, me he dado cuenta que hay mucho por hacer, pero estoy seguro que con nuevo Director y el apoyo de todos los miembros de la comunidad universitaria, es posible colocar la Revista Científica MANGLAR, y por ende a la Universidad Nacional de Tumbes, en el sitial que les corresponde.

Dr. Oscar Augusto Mendoza Neyra Jefe de la Oficina de Investigación Universidad Nacional de Tumbes 